\title{
Functional Capacity, Skeletal Muscle Strength, and Skeletal Muscle Volume in Patients With Myocardial Infarction
}

\author{
Keisuke KIDA, ${ }^{1}$ MD, Naohiko OsADA, ${ }^{1}$ MD, Yoshihiro J. AKASHI, ${ }^{1}$ MD, \\ Hiromitsu SEKIZUKA, ${ }^{1} \mathrm{MD}$, Masaki IzUMO, ${ }^{1} \mathrm{MD}$, Yuki IsHIBAshI, ${ }^{1} \mathrm{MD}$, \\ Takashi ShImozato, ${ }^{1}$ MD, Akio Hayashi, ${ }^{1} \mathrm{MD}$, Kihei YoneYAmA, ${ }^{1} \mathrm{MD}$, \\ Eiji TAKAHASHI, ${ }^{1}$ MD, Kengo SuzUKI, ${ }^{1}$ MD, Masachika TAMURA, ${ }^{1}$ MD, \\ Koji Inoue, ${ }^{1}$ MD, Kazuto OMIYA, ${ }^{1}$ MD, and Fumihiko MiYaKe, ${ }^{1}$ MD
}

\section{SUMMARY}

Previous studies have reported that skeletal muscle strength is closely related to exercise capacity in patients with myocardial infarction (MI). However, none of the previous studies have fully investigated the correlation between exercise capacity and the skeletal muscle volume (MV). Seventy patients with MI underwent symptom-limited cardiopulmonary exercise testing using a treadmill. The MV was evaluated by electrical impedance analysis and the maximal knee extension strength (Peak torque: PT) was measured by a Biodex. The subjects were divided into 2 groups according to the MV (group L, MV < $22 \mathrm{~kg}$; group $\mathrm{H}, \mathrm{MV} \geqq 22 \mathrm{~kg}$ ). The PT was positively and significantly correlated with the peak $\dot{\mathrm{V}}_{2}$ in both the $\mathrm{L}$ and $\mathrm{H}$ groups $(r=0.70$ versus $r=0.71)$. The MV of the lower limbs was positively correlated with the peak $\mathrm{VO}_{2}$ in the $\mathrm{L}$ group $(r=0.57)$, but not in the $\mathrm{H}$ group. The lower limb MV was positively and significantly correlated with PT in the $\mathrm{L}$ group $(r=0.48)$, but not in the $\mathrm{H}$ group. The exercise capacity of patients with MI is thought to depend on both the strength and volume of the skeletal muscle. In MI patients with high muscle volume, exercise capacity was determined by skeletal muscle strength alone. (Int Heart J 2006; 47: 727-738)

Key words: Exercise capacity, Skeletal muscle strength, Skeletal muscle volume, Myocardial infarction

CARDIAC rehabilitation is well known to facilitate functional improvement in patients with acute myocardial infarction (AMI) ${ }^{1-5)}$ and patients with chronic heart failure (CHF). ${ }^{6-10)}$ Peripheral factors are believed to play more important roles than central factors in the mechanisms of functional improvement. ${ }^{3,5,11-14)}$ One peripheral factor, skeletal muscle strength, has been shown to be closely

\footnotetext{
From the Division of Cardiology, Department of Internal Medicine, St. Marianna University School of Medicine, Kanagawa, Japan.

Address for correspondence: Keisuke Kida, MD, Division of Cardiology, Department of Internal Medicine, St. Marianna University School of Medicine, 2-16-1 Sugao, Miyamae-ku, Kawasaki-city, Kanagawa 216-8511, Japan.

Received for publication July 4, 2006.

Revised and accepted September 11, 2006. 
related to exercise capacity in patients with cardiac diseases. ${ }^{2,15-17)}$ Murabayashi, et $a l^{3)}$ found that physical training in patients with MI led to both functional improvements and improvements in peripheral factors such as skeletal muscle volume. In a study by Beniamini, et $a l,{ }^{18)}$ high-intensity strength training helped to improve exercise capacity and to change body composition. Data from Ades, et $a l^{5)}$ suggested that the adaptation of peripheral skeletal muscle was the most important determinant of exercise capacity in elderly patients with coronary diseases. On the other hand, there have been few studies designed to investigate the relationship between skeletal muscle volume and exercise capacity in patients with MI. ${ }^{3}$ One study noted an association between skeletal muscle volume and exercise capacity in patients who had undergone coronary artery bypass graft surgeries (CABG) ${ }^{19)}$ Several others revealed correlations between skeletal muscle volume and exercise capacity in patients with $\mathrm{CHF}^{15,20-23)}$ If a similar correlation exists in patients with MI, it remains uncertain whether such a correlation could be found to influence the exercise capacity of the patient. The present study had two objectives: first, to evaluate skeletal muscle volume as a determinant of skeletal muscle strength in a population of MI patients, and second, to evaluate the correlation between skeletal muscle volume and skeletal muscle strength in relation to exercise capacity in the same patients.

\section{METHODS}

Subjects: The study was conducted on a population of $70 \mathrm{MI}$ patients (mean age, $60.3 \pm 10.3$ years old) from May 2003 to June 2005 at St. Marianna University School of Medicine Hospital in Kawasaki, Japan. The patient backgrounds are shown in Table I. Thirty-eight of the subjects had anterior MI, 22 had inferior MI, and 10 had lateral MI. Patients with postinfarction angina, critical arrhythmia, and/or uncontrolled heart failure were excluded. All subjects underwent physical training after the onset of MI. Percutaneous coronary intervention (PCI), coronary thrombolysis, and conservative medical treatment during the acute phase of MI were performed in 58, 3, and 9 subjects, respectively. Forty of the subjects with MI had one-vessel disease, 26 had two-vessel disease, and 4 had three-vessel disease. All subjects remained clinically stable after the onset of MI, and none were hospitalized or had any changes to their medications after discharge.

Ethics: The present study was approved by the St. Marianna University School of Medicine Institutional Committee on Human Research. Informed consent was obtained from all of the patients prior to their enrollment.

Cardiopulmonary exercise testing: Symptom-limited cardiopulmonary exercise testing (CPX) was performed at 1 month after the onset of MI using a MAT-2500 treadmill (Fukuda Denshi Co., Tokyo, Japan). After an initial 3-minute rest on the 
Table I. Patients Characteristics

\begin{tabular}{|c|c|c|c|c|}
\hline & & L group & $\mathrm{H}$ group & $P$ \\
\hline Number & 70 & 37 & 33 & NS \\
\hline Male/Female & $70 / 0$ & $37 / 0$ & $33 / 0$ & NS \\
\hline Age (year) & $60.3 \pm 10.3$ & $59.7 \pm 9.8$ & $61.0 \pm 10.9$ & NS \\
\hline Height $(\mathrm{cm})$ & $166.3 \pm 7.2$ & $164.8 \pm 6.7$ & $168.0 \pm 7.5$ & NS \\
\hline Weight (kg) & $65.1 \pm 8.6$ & $60.0 \pm 6.4$ & $70.8 \pm 6.9$ & $<0.0001$ \\
\hline $\operatorname{BMI}\left(\mathrm{kg} / \mathrm{m}^{2}\right)$ & $23.5 \pm 2.9$ & $22.0 \pm 2.2$ & $25.2 \pm 2.7$ & $<0.0001$ \\
\hline \multicolumn{5}{|l|}{ NYHA classification } \\
\hline I & 17 & 9 & 8 & NS \\
\hline II & 32 & 17 & 15 & NS \\
\hline III & 21 & 11 & 10 & NS \\
\hline IV & 0 & 0 & 0 & NS \\
\hline \multicolumn{5}{|l|}{ Cardiac function } \\
\hline $\mathrm{EF}(\%)$ & $51.7 \pm 11.9$ & $51.9 \pm 12.2$ & $51.6 \pm 11.7$ & NS \\
\hline AT $(\mathrm{mL} / \mathrm{min} / \mathrm{kg})$ & $18.9 \pm 3.5$ & $18.5 \pm 3.6$ & $19.3 \pm 3.3$ & NS \\
\hline Peak $\dot{\mathrm{V}} \mathrm{O}_{2}(\mathrm{~mL} / \mathrm{min} / \mathrm{kg})$ & $27.1 \pm 4.9$ & $26.7 \pm 5.1$ & $27.6 \pm 4.6$ & NS \\
\hline \multicolumn{5}{|l|}{ Medication } \\
\hline ACE-I & $27(39 \%)$ & $14(38 \%)$ & $13(39 \%)$ & NS \\
\hline A-II & $36(51 \%)$ & $20(54 \%)$ & $16(48 \%)$ & NS \\
\hline Beta-blockade & $12(17 \%)$ & $8(22 \%)$ & $4(12 \%)$ & NS \\
\hline Diuretics & $10(14 \%)$ & $5(14 \%)$ & $5(15 \%)$ & NS \\
\hline Nitrate & $57(81 \%)$ & $29(78 \%)$ & $28(85 \%)$ & NS \\
\hline Digoxin & $0(0 \%)$ & $0(0 \%)$ & $0(0 \%)$ & NS \\
\hline Calcium blockade & $13(19 \%)$ & $8(22 \%)$ & $5(15 \%)$ & NS \\
\hline
\end{tabular}

BMI indicates body mass index; NYHA, New York Heart Association; EF, ejection fraction; AT, anaerobic threshold; Peak $\dot{\mathrm{V}} \mathrm{O}_{2}$, peak oxygen uptake; ACE-I, angiotensin converting enzyme inhibitor; and A-II, angiotensin-II antagonist.

Values are expressed as the mean \pm S.D.

treadmill and 3-minute warm-up (speed $1.6 \mathrm{~km} / \mathrm{h}$; grade $0 \%$ ), the subjects underwent the CPX at a gradually increasing intensity (load increased at 1-minute intervals). The 12-lead ECGs were monitored continuously and heart rate (HR) was measured with the R-R interval of the ECG (ML-5000, Fukuda Denshi Co.). The systolic blood pressure was measured with a cuff via an automatic blood pressure monitor (Stress Test System, STBP-780, Colin, Aichi, Japan) at 1minute intervals. Expired gas analysis was performed throughout the test by the breath-by-breath method with an AE-280 cart (Minato Medical Science, Osaka, Japan). The anaerobic threshold (AT) and peak oxygen uptake (peak $\dot{\mathrm{V}} \mathrm{O}_{2}$ ) were calculated from the results of the CPX. AT was determined by the original Vslope method. ${ }^{24)}$ The criteria to halt the exercise test in this study were determined according to the guidelines of the American College of Sports Medicine. ${ }^{25}$ An apparent leveling off of $\dot{\mathrm{V}} \mathrm{O}_{2}\left(\mathrm{a} \dot{\mathrm{V}} \mathrm{O}_{2}\right.$ plateau in spite of increasing exercise intensity) was used as a sign to terminate the exercise.

Measurement of skeletal muscle volume: Before starting CPX, the muscle vol- 
ume was measured by a single-cycle bioelectrical impedance data acquisition system $^{26)}$ (Muscle- $\alpha$, Art Haven 9 Co., Kyoto, Japan). Each subject was asked to rest quietly on a bed in the supine position. The 4 limbs were fully extended straight outward from the trunk at $30^{\circ}$ angles to ensure that none touched any of the others. After attaching the electrodes to the distal most finger and toe of each extremity, a voltage determination electrode was also attached to each extremity as an impedance determination locus. Electrodes were attached to 12 measurement sites in total: the root of the middle finger on the dorsum of each hand, the dorsal side of each wrist, the root of the middle toe on the dorsum of each foot, the center of the dorsal side of each ankle, and the lateral side of each elbow and knee. The subjects were divided into 2 groups according to the skeletal muscle volume that was the mean value (group L, muscle volume $<22 \mathrm{~kg}$; group $\mathrm{H}$, muscle volume $\geq 22 \mathrm{~kg}$ ).

Measurement of muscular strength: A Biodex System 2 isokinetic dynamometer (Biodex Medical Systems, Inc, New York, NY, USA) was used to measure knee extension muscular strength (Peak torque: PT), an index of the muscular strength of the lower limb. The machine was calibrated at initiation of the study. Subjects underwent the test in a seated position with hip flexion at $80^{\circ}$ and stabilization straps applied to the trunk, waist, and thighs. The resistance pad was placed 10 $\mathrm{cm}$ proximal to the medial malleoulus. The range of motion during the test was set between $0^{\circ}$ and $90^{\circ}$ for knee flexion. All patients performed 3-time submaximal and 1-time maximal warm-up at the test speed prior to the test. ${ }^{27)}$ The test was repeated 5 times at most, at isokinetic speeds of $60^{\circ}$ per second. These isokinetic test results were analyzed using Biodex System 2 software. The maximum value was obtained as an index of knee extension muscular strength (peak PT).

Statistical analysis: All values are presented as the mean \pm standard deviation. Student's $t$ test was used to compare the mean values of parameters between the 2 groups. Spearman's regression analysis was used to analyze the correlations of 2 parameters. The level of statistical significance for measurements was set at less than $5 \%$.

\section{Results}

No patients suffered from any major complications such as exacerbation of heart failure, sudden cardiac death, or any other cardiac event during the study period. No significant differences in age, left ventricular ejection fraction, New York Heart Association Functional Classification, peak $\stackrel{\dot{\mathrm{V}}}{\mathrm{O}_{2}}$, or AT were observed between the $\mathrm{L}$ and $\mathrm{H}$ groups (Table I).

Exercise capacity: The end-point of the exercise test was determined by leg fatigue and shortness of breath. No patients showed ischemic ST changes or 
Table II. Exercise Capacity, Muscle Volume, and Strength

\begin{tabular}{lrccc}
\hline & & L group & H group & $P$ \\
\hline Exercise & & & & \\
$\quad \mathrm{AT}(\mathrm{mL} / \mathrm{min})$ & $1232 \pm 290$ & $1113 \pm 254$ & $1365 \pm 272$ & $<0.0005$ \\
Peak $\dot{\mathrm{V} O}(\mathrm{~mL} / \mathrm{min})$ & $1774 \pm 435$ & $1607 \pm 380$ & $1962 \pm 420$ & $<0.0005$ \\
$\mathrm{VE} / \mathrm{CO}_{2}$ slope $(\mathrm{mL} / \mathrm{mL})$ & $29.2 \pm 4.7$ & $29.1 \pm 5.5$ & $29.3 \pm 3.7$ & $\mathrm{NS}$ \\
Muscle volume $(\mathrm{Kg})$ & & & & \\
$\quad$ Whole body & $21.8 \pm 2.8$ & $19.6 \pm 1.6$ & $24.2 \pm 1.6$ & $<0.0001$ \\
$\quad$ Superior & $1.3 \pm 0.2$ & $1.1 \pm 0.2$ & $1.4 \pm 0.2$ & $<0.0001$ \\
$\quad$ Inferior limb & $4.9 \pm 0.6$ & $4.5 \pm 0.4$ & $5.4 \pm 0.4$ & $<0.0001$ \\
$\quad$ Thigh & $3.0 \pm 0.5$ & $2.7 \pm 0.3$ & $3.3 \pm 0.3$ & $<0.0001$ \\
$\quad$ Crus & $2.0 \pm 0.3$ & $1.8 \pm 0.2$ & $2.2 \pm 0.2$ & $<0.0001$ \\
Peak torque $(\mathrm{N} \mathrm{m})$ & & & & \\
$\quad$ Right & $119.9 \pm 35.7$ & $108.1 \pm 33.3$ & $133.1 \pm 34.0$ & $<0.005$ \\
$\quad$ Left & $117.1 \pm 36.1$ & $107.8 \pm 34.8$ & $127.9 \pm 35.2$ & $<0.05$ \\
$\quad$ Peak & $125.0 \pm 35.9$ & $113.4 \pm 34.5$ & $137.9 \pm 33.3$ & $<0.005$ \\
\hline
\end{tabular}

AT indicates anaerobic threshold and Peak $\dot{\mathrm{VO}}_{2}$, peak oxygen uptake.

Values are expressed as the mean \pm S.D.
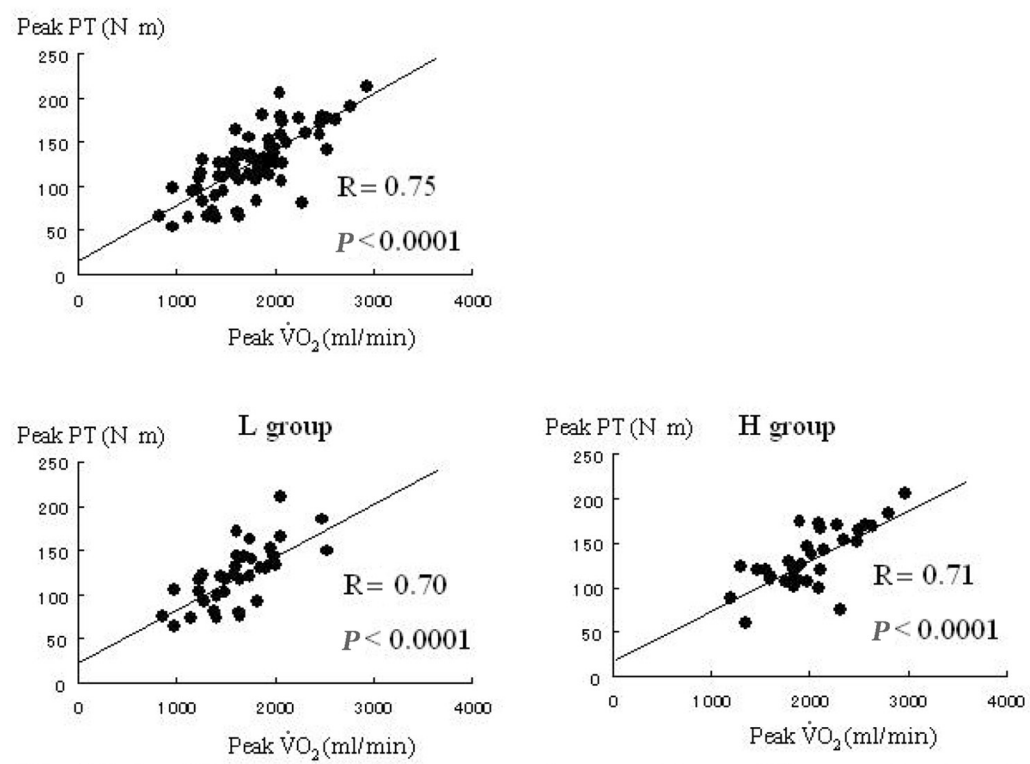

Figure 1. Correlations between muscle strength and exercise capacity.

Positive correlations were found between PT and peak $\dot{\mathrm{VO}}_{2}$. Significant positive correlations between PT and peak $\dot{\mathrm{V}} 2$ were found in both the $\mathrm{L}$ and $\mathrm{H}$ groups. $\mathrm{PT}$ indicates peak torque and $\dot{\mathrm{VO}}_{2}$, oxygen uptake.

experienced chest pain or serious arrhythmia during the exercise test. AT was $1232 \pm 290 \mathrm{~mL} / \mathrm{min}(18.9 \pm 3.5 \mathrm{~mL} / \mathrm{min} / \mathrm{kg})$ and peak $\dot{\mathrm{V}}_{2}$ was $1774 \pm 435 \mathrm{~mL} /$ $\min (27.1 \pm 4.9 \mathrm{~mL} / \mathrm{min} / \mathrm{kg})($ Table II). 
Skeletal muscle volume and skeletal muscle strength: The skeletal muscle volumes of the whole body, upper limbs, and lower limbs were $21.8 \pm 2.8,1.3 \pm 0.2$, and $4.9 \pm 0.6 \mathrm{~kg}$, respectively, as shown in Table II. The lower limb muscle volume included the muscle volume of the thighs $(3.0 \pm 0.5 \mathrm{~kg})$ and crus $(2.0 \pm 0.3$ $\mathrm{kg})$. The PT was $119.9 \pm 35.7 \mathrm{Nm}(1.8 \pm 0.5 \mathrm{Nm} / \mathrm{kg})$ on the right side and 117.1 $\pm 36.1 \mathrm{Nm}(1.8 \pm 0.5 \mathrm{Nm} / \mathrm{kg})$ on the left side. The peak PT was $125.0 \pm 35.9 \mathrm{Nm}$ $(1.9 \pm 0.5 \mathrm{Nm} / \mathrm{kg})$.

Relationship between skeletal muscle strength and exercise capacity: The peak PT was positively correlated with both the AT $(r=0.68, P<0.0001)$ and peak $\dot{\mathrm{VO}}_{2}$ $(r=0.75, P<0.0001)$ (Figure 1). Significant positive correlations between muscle strength and peak $\dot{\mathrm{V}} \mathrm{O}_{2}$ were found in both the $\mathrm{L}$ and $\mathrm{H}$ groups $(r=0.70, P<$ $0.0001 ; r=0.71, P<0.0001$ ) (Figure 1).

Relationship between skeletal muscle volume and exercise capacity: The skeletal muscle volumes of the whole body, upper limb, lower limb, thigh, and crus were all significantly and positively correlated with both the AT (whole body, $r=0.54$, $P<0.0001$; upper limb, $r=0.44, P<0.005$; lower limb, $r=0.54, P<0.0001$; thigh, $r=0.62, P<0.0001$; crus, $r=0.33, P<0.01$ ) and peak $\dot{\mathrm{V}} \mathrm{O}_{2}$ (whole body, $r=0.53, P<0.0001$; upper limb, $r=0.55, P<0.0001$; lower limb, $r=0.55, P<$
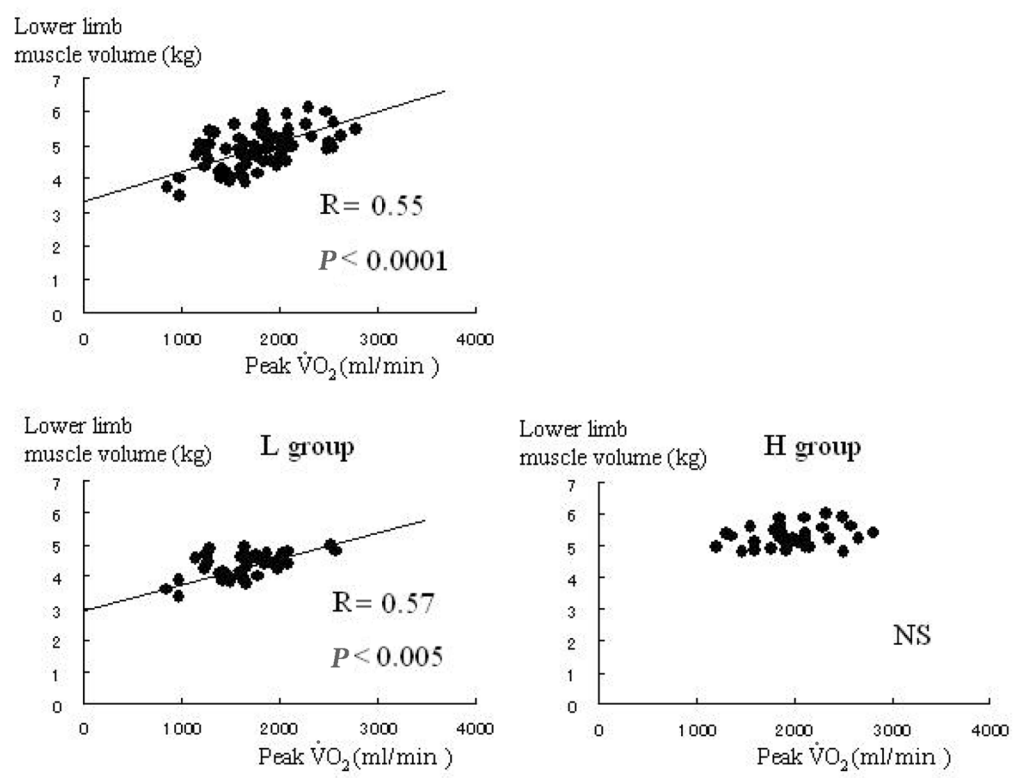

Figure 2. Correlations between muscle volume and exercise capacity.

Positive correlations were found between lower limb skeletal muscle volume and peak $\dot{\mathrm{V}} \mathrm{O}_{2}$. The correlation between the lower limb skeletal muscle volume and peak $\mathrm{VO}_{2}$ was significant and positive in the $\mathrm{L}$ group, but not in the $\mathrm{H}$ group. $\dot{\mathrm{VO}}_{2}$ indicates oxygen uptake. 

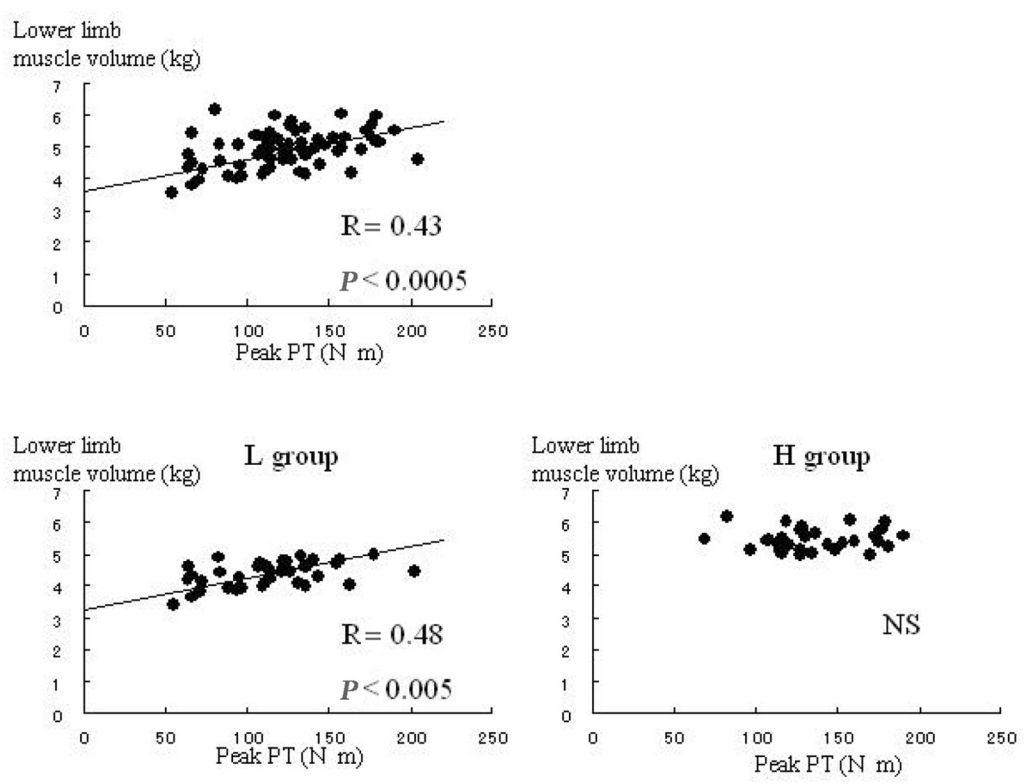

Figure 3. Correlations between muscle strength and muscle volume.

Positive correlations were found between peak PT and lower limb skeletal muscle volume. Lower limb skeletal muscle volume was significantly and positively correlated with peak PT in the L group, but not in the H group. PT indicates peak torque.

0.0001 ; thigh, $r=0.66, P<0.0001$; crus, $r=0.40, P<0.001)$ (Figure 2). The correlation between the lower limb skeletal muscle volume and peak $\dot{\mathrm{V}} \mathrm{O}_{2}$ was significant and positive in the $\mathrm{L}$ group $(r=0.57, P<0.0005)$ but not in the $\mathrm{H}$ group (Figure 2).

Relationship between skeletal muscle strength and skeletal muscle volume: The skeletal muscle volumes of the whole body, upper limb, lower limb, thigh, and crus were all significantly and positively correlated with the peak PT (whole body, $r=0.41, P<0.0005$; upper limb, $r=0.50, P<0.0001$; lower limb, $r=0.43$, $P<0.0005$; thigh, $r=0.52, P<0.0001$; crus, $r=0.35, P<0.005$ ) (Figure 3 ).

The lower limb skeletal muscle volume was significantly and positively correlated with the peak PT in the $\mathrm{L}$ group $(r=0.48, P<0.005)$, but not in the $\mathrm{H}$ group (Figure 3).

\section{DISCUSSION}

Peak $\dot{\mathrm{V}} \mathrm{O}_{2}$ is a useful index for the analysis of exercise capacity and a strong prognostic marker in patients with MI and CHF. Few studies, however, have sought to clarify how reduced exercise capacity relates to reductions in central 
factors such as cardiac output, left ventricular ejection fraction, and lung function. ${ }^{28,29)}$ While some reports have confirmed correlations between exercise capacity and blood flow and skeletal muscle metabolism, ${ }^{12,14)}$ none have actually measured skeletal muscle volume and strength to determine how these 2 parameters correlate with exercise capacity or with each other. This study investigated the influence of skeletal muscle volume on exercise capacity in a relatively large population of patients with MI using bioelectricity impedance, a new method for measuring skeletal muscle volume. The present study was performed based on a hypothesis that the relationship between exercise capacity, skeletal muscle strength, and skeletal muscle volume might be changed by the amount of skeletal muscle volume in patients with MI. Exercise capacity in patients with low skeletal muscle volume was influenced strongly by skeletal muscle volume. Therefore, we divided all subjects into 2 groups in this study population. Skeletal muscle volume has generally been measured by dual X-ray absorptiometry (DEXA) in earlier studies. The present study is actually the first to apply the bioelectricity impedance method for the measurement of skeletal muscle volume in patients with MI. Computerized tomography (CT), DEXA, and magnetic resonance imaging (MRI) are all more expensive and time consuming than the bioelectricity impedance method, and CT and DEXA both expose subjects to radiation. ${ }^{30)}$ Since the bioelectricity impedance method is safe, reliable, portable, and relatively inexpensive, it is recommended for the measurement of skeletal muscle volume. ${ }^{31)}$ Other recent studies have also applied bioelectricity impedance analysis for the quantification of skeletal muscle volume. ${ }^{26,31,32)}$

This study was designed to clarify 2 points in MI patients. First, to measure skeletal muscle volume, an important determinant of skeletal muscle strength, and second, to evaluate the influences of skeletal muscle volume and skeletal muscle strength on exercise capacity in patients with MI.

Relationship between skeletal muscle strength and exercise capacity: Recent reports have identified significant correlations between skeletal muscle strength and exercise capacity in the elderly, ${ }^{33)}$ in patients with $\mathrm{MI},{ }^{34)}$ and in patients with CHF. ${ }^{15-17)}$ Other reports have also suggested that high-intensity knee extensor training improves exercise capacity in patients with $\mathrm{MI}^{18)}$ and CHF. ${ }^{35)}$ Skeletal muscle strength was found to be one of the most important positive correlates of exercise capacity in patients with MI. ${ }^{34)}$ The relationship between skeletal muscle strength and exercise capacity in our study was very similar to that demonstrated by Yamasaki, et al, ${ }^{34)}$ and the similarity was common to both the $\mathrm{H}$ and $\mathrm{L}$ groups. The good correlation between skeletal muscle strength and exercise capacity in our MI patients was not dependent on muscle volume. Anker, et al ${ }^{15)}$ found a positive relationship between skeletal muscle strength and exercise capacity in noncachectic patients with $\mathrm{CHF}$, but not in cachectic patients. 
Skeletal muscle volume in MI patients in the L group was somewhat smaller than that of the $\mathrm{H}$ group in this study, but this difference would not have been found if our patients had been cachectic. Cachectic patients with $\mathrm{CHF}$ are characterized not only by small muscle volume, but also endocrine, catabolic, or cytokine abnormalities that apparently lead to qualitative changes in the skeletal muscle such as increased Type IIb fiber, decreased Type I fiber, and decreased mitochondria volume ${ }^{11,38)}$ in skeletal muscle biopsy. We believe that these types of qualitative changes were responsible for the discrepancy in the results in MI patients.

Relationship between skeletal muscle volume and exercise capacity: Several previous studies have provided results consistent with our own by recognizing significant correlations between skeletal muscle volume and exercise capacity in patients with $\mathrm{MI}^{3)}$ and $\mathrm{CHF} .{ }^{15,20-23)}$ As in our study, Murabayashi, et $a l^{3)}$ found a significant correlation between skeletal muscle volume and exercise capacity in patients with MI.

The exercise capacity of our MI patients was significantly correlated to their skeletal muscle strength but not to their skeletal muscle volume. Ours is the only study to report this result, and we attribute the result to the decreasing correlation in our patients with relatively high skeletal muscle volumes. Skeletal muscle volume significantly contributed to exercise capacity in the L group in our study, but not in the $\mathrm{H}$ group.

Relationship between skeletal muscle strength and skeletal muscle volume: Previous studies have shown significant correlations between the peak PT and skeletal muscle volume in the elderly ${ }^{33)}$ and in patients with CHF. ${ }^{39)}$ Neither of these studies showed a similar correlation in patients with MI, however. The results of the present study in MI patients demonstrated a significant positive correlation between peak PT and skeletal muscle, especially in the skeletal muscle of the thighs. The results of the present study differ from those of previous studies, and no such correlation was observed in our MI patients with relatively high skeletal muscle volume. We speculate that de-conditioning or other factors might have prevented our patients with high skeletal muscle volume from correctly exhibiting their skeletal muscle strength. We thus recognize a need for future clinical studies to investigate why patients with high skeletal muscle volume are unable to correctly apply the full strength of their skeletal muscles.

Study limitations: The data obtained in the present study were not sufficient to evaluate 2 significant points; namely, the change in skeletal muscle volume induced by exercise training, and the influence of exercise training on the relationship among skeletal muscle volume, exercise capacity, and skeletal muscle strength. Since we did not perform muscle biopsies of the lower extremities, we were unable to adequately observe muscle tissue change. We also did not evaluate 
distal skeletal muscle blood flow at rest and during exercise. Future studies will have to address these points neglected here. Our evaluations of skeletal muscle strength were also lacking, as we based them on peak torque alone rather than peak torque and muscle endurance in combination. Future studies should also evaluate muscle endurance to improve the reliability of data on skeletal muscle strength.

Conclusions: The exercise capacity of patients with myocardial infarction is thought to depend on both the strength and volume of the skeletal muscle. Our results indicated that this was true in MI patients with low muscle volume. In MI patients with high muscle volume, exercise capacity was determined by skeletal muscle strength alone.

\section{ACKNOWLEDGEMENTS}

We thank Mr. Satoshi Watanabe, Mr. Kazuhiro Izawa, and the cardiac rehabilitation staff from the Department of Rehabilitation Medicine at St. Marianna University Hospital for their technical assistance in this study.

\section{REFERENCES}

1. Giannuzzi P, Tavazzi L, Temporelli PL, et al. Long-term physical training and left ventricular remodeling after anterior myocardial infarction: results of Exercise in Anterior Myocardial Infarction (EAMI) trial. EAMI Study Group. J Am Coll Cardiol 1993; 22: 1821-9.

2. Yamasaki H, Yamada S, Tanabe K, et al. Effects of weight training on muscle strength and exercise capacity in patients after myocardial infarction. J Cardiol 1995; 26: 341-7. (Japanese)

3. Murabayashi T, Itoh H, Kato M, Tanabe K, Kato K. Mechanism of increase in exercise tolerance in patients with acute myocardial infarction. J Cardiol 1997; 30: 241-9. (Japanese)

4. Oya M, Itoh H, Kato K, Tanabe K, Murayama M. Effects of exercise training on the recovery of the autonomic nervous system and exercise capacity after acute myocardial infarction. Jpn Circ J 1999; 63: 843-8.

5. Ades PA, Waldmann ML, Meyer WL, et al. Skeletal muscle and cardiovascular adaptations to exercise conditioning in older coronary patients. Circulation 1996; 94: 323-30.

6. Sullivan MJ, Higginbotham MB, Cobb FR. Exercise training in patients with severe left ventricular dysfunction. Circulation 1988; 78: 506-15.

7. Sullivan MJ, Higginbotham MB, Cobb FR. Exercise training in patients with chronic heart failure delays ventilator anaerobic threshold and improves sub maximal exercise performance. Circulation 1989; 79: 324-9.

8. Coats AJ, Adamopoulos S, Radaelli A, et al. Controlled trial of physical training in chronic heart failure. Exercise performance, hemodynamic, ventilation, and autonomic function. Circulation 1992; 85: 2119-31.

9. McKelvie RS, Teo KK, McCartney N, Humen D, Montague T. Effects of exercise training in patients with congestive heart failure: a critical review. J Am Coll Cardiol 1995; 25: 789-96. (Review)

10. Afzal A, Brawner CA, Keteyian SJ. Exercise training in heart failure. Prog Cardiovasc Dis 1998; 41: 175-90. (Review)

11. Hambrecht R, Niebauer J, Fiehn E, et al. Physical training in patients with stable chronic heart failure: effects on cardiorespiratory fitness and ultrastructural abnormalities of leg muscles. J Am Coll Cardiol 1995; 25: 123949.

12. Hattori T, Sumimoto T, Yuasa F, et al. Influence of intrinsic limb vasodilator capacity on exercise tolerance in patients with recent myocardial infarction. Am Heart J 1999; 132: 593-8. 
13. Okita K, Yonezawa K, Nishijima H, et al. Skeletal muscle metabolism limits exercise capacity in patients with chronic heart failure. Circulation 1998; 98: 1886-91.

14. Akashi YJ, Koike A, Osada N, Omiya K, Itoh H. Short-term physical training improves vasodilatory capacity in cardiac patients. Jpn Heart J 2002; 43: 13-24.

15. Anker SD, Swan JW, Volterrani M, et al. The influence of muscle mass, strength, fatigability and blood flow on exercise capacity in cachectic and non-cachectic patients with chronic heart failure. Eur Heart J 1997; 18: 25969.

16. Sato S, Arakawa N, Kamata J, et al. Relationship between exercise tolerance and respiratory pattern and muscular strength of legs in patients with chronic heart failure. J Phys Ther Sci 2002; 14: 47-50.

17. Suzuki K, Omiya K, Yamada S, et al. Relations between strength and endurance of leg skeletal muscle and cardiopulmonary exercise testing parameters in patients with chronic heart failure. J Cardiol 2004; 43: 59-68.

18. Beniamini Y, Rubenstein JJ, Faigenbaum AD, Lichtenstein AH, Crim MC. High-intensity strength training of patients enrolled in an outpatient cardiac rehabilitation program. J Cardiopulm Rehabil 1999; 19: 8-17.

19. Murabayashi $\mathrm{T}$, Itoh $\mathrm{H}$, Kato $\mathrm{M}$, et al. Factor affecting exercise capacity after coronary bypass grafting. Kyoubu Geka 1997; 50: 450-8. (Japanese)

20. Miyagi K, Asanoi H, Ishizaka S, et al. Importance of total leg muscle mass for exercise intolerance in chronic heart failure. Jpn Heart J 1994; 35: 15-26.

21. Lang CC, Chomsky DB, Rayos G, Yeoh TK, Wilson JR. Skeletal muscle mass and exercise performance in stable ambulatory patients with heart failure. J Appl Physiol 1997; 82: 257-61.

22. Toth MJ, Gottlieb SS, Fisher ML, Poehlman ET. Skeletal muscle atrophy and peak oxygen consumption in heart failure. Am J Cardiol 1997; 79: 1267-9.

23. Cicoira M, Zanolla L, Franceschini L, et al. Skeletal muscle mass independently predicts peak oxygen consumption and ventilatory response during exercise in noncachetic patients with chronic heart failure. J Am Coll Cardiol 2001; 37: 2080-5.

24. Beaver WL, Wasserman K, Whipp BJ. A new method for detecting anaerobic threshold by gas exchange. J Appl Physiol 1986; 60: 2020-27.

25. American College of Sports Medicine. In: ACSM's Guidelines for Exercise Testing and Prescription. Johnson EP, ed. Clinical exercise testing. $6^{\text {th }}$ ed. Baltimore: Williams \& Wilkins; 2000: 91-114.

26. Miyatani M, Kanehisa H, Masuo Y, Ito M, Fukunaga T. Validity of estimating limb muscle volume by bioelectrical impedance. J Appl Physiol 2001; 91: 386-94.

27. Wilk KE, Romaniello WT, Soscia SM, Arrigo CA, Andrews JR. The relationship between subjective knee scores, isokinetic testing, and functional testing in the ACL-reconstructed knee. J Orthop Sports Phys Ther 1994; 20: 60-73.

28. Higginbotham MB, Morris KG, Conn EH, Coleman RE, Cobb FR. Determinants of variable exercise performance among patients with severe left ventricular dysfunction. Am J Cardiol 1983; 51: 52-60.

29. Sullivan MJ, Hawthorne MH. Exercise intolerance in patients with chronic heart failure. Prog Cardiovascular Dis 1995; 38: 1-22. (Review)

30. Heymsfield SB, Smith R, Aulet M, et al. Appendicular skeletal muscle mass: measurement by dual photon absorptiometry. Am J Clin Nutr 1990; 52: 214-8.

31. Baumgartner RN, Ross R, Heymsfield SB. Does adipose tissue influence bioelectric impedance in obese men and women? J Appl Physiol 1998; 84: 257-62.

32. Janssen I, Heymsfield SB, Baumgartner RN, Ross R. Estimation of skeletal muscle mass by bioelectrical impedance analysis. J Appl Physiol 2000; 89: 465-71.

33. Reed RL, Pearlmutter L, Yochum K, Meredith KE, Mooradian AD. The relationship between muscle mass and muscle strength in the elderly. J Am Geriatr Soc 1991; 39: 555-61.

34. Yamasaki H, Yamada S, Watanabe S, et al. Muscle strength of lower extremities in patients with myocardial infarction; Relationship between leg muscle strength and exercise capacity. Sogo Reha 1994; 22: 41-4. (Japanese)

35. Magnusson G, Gordon A, Kaijser L, et al. High intensity knee extensor training in patients with chronic heart failure. Major skeletal muscle improvement. Eur Heart J 1996; 17: 1048-55.

36. Larsen AI, Lindal S, Aukrust P, Toft I, Aarsland T, Dickstein K. Effect of exercise training on skeletal muscle fibre characteristics in men with chronic heart failure. Correlation between skeletal muscle alterations, cytokines and exercise capacity. Int J Cardiol 2002; 83: 25-32. 
37. Sullivan MJ, Green HJ, Cobb FR. Skeletal muscle biochemistry and histology in ambulatory patients with long-term heart failure. Circulation 1990; 81: 518-27.

38. Drexler H, Riede U, Munzel T, Koning H, Funke E, Just H. Alterations of skeletal muscle in chronic heart failure. Circulation 1992; 85: 1751-9.

39. Harrington D, Anker SD, Chua TP, et al. Skeletal muscle function and its relation to exercise tolerance in chronic heart failure. J Am Coll Cardiol 1997; 30: 1758-64. 